\title{
CUIDADO HUMANIZADO NOS SERVIÇOS DE URGÊNCIA/EMERGÊNCIA: REVISÃO INTEGRATIVA
}

\author{
HUMANIZED CARE IN URGENCY/EMERGENCY SERVICES: INTEGRATIVE \\ REVIEW
}

\author{
Rafaela Lorena Soares Santos \\ Universidade Estadual De Santa Cruz - UESC
}

\begin{abstract}
The article aims to identify in the scientific production related to the humanized care in the emergency / urgency services the obstacles and facilities for the humanized care in these services. This is an integrative review of the literature in the National Health Library databases. The following inclusion criteria were used: complete articles indexed in the VHL independent of the database, published in Portuguese in the last five years, that were available for reading, and that met the objectives of the study. Exclusion criteria were defined as: studies that did not address the proposed objectives, which had the subject of emergency pre-hospital emergency services and pediatric emergency services, duplicate articles and did not meet the inclusion criteria. Results: We selected 13 articles. The results pointed out as obstacles to humanized care the overcrowding, Inverted flow, User ignorance, Physical structure and material resources, Management, Personnel Dimensioning and Multiprofessional Team and Working conditions. Regarding the facilitators and suggestions were pointed out Interpersonal Relationship, Training, Management Participation and Service Restructuring. Conclusion: In the light of the foregoing, it is possible to conclude that for humanized care in emergency / emergency services a multifactorial approach is necessary in order to eradicate or at least mitigate the obstacles presented.
\end{abstract}

Key words: Humanization of Assistance; Emergencies; User Embracement.
Resumo

O artigo tem como objetivo identificar na produção científica relacionada ao cuidado humanizado nos serviços de urgência/emergência quais os entraves $e$ facilidades para o cuidado humanizado nesses serviços. Trata-se de uma revisão integrativa da literatura nas bases de dados da Biblioteca Virtual em Saúde. Utilizou-se como critérios de inclusão: artigos completos indexados na BVS independente do banco de dados, publicados em português, nos últimos cinco anos, que estivessem disponíveis para leitura, e que atendessem aos objetivos do estudo. Como critérios de exclusão delimitou-se: estudos que não abordassem os objetivos propostos, que tivessem como temática serviços de emergência pré-hospitalar móvel e serviços de emergência pediátrica, artigos duplicados e que não atendessem aos critérios de inclusão. Foram selecionados 13 artigos. Os resultados apontaram como entraves para o cuidado humanizado a Superlotação, Fluxo invertido, Desconhecimento do usuário, Estrutura física $e$ recursos materiais, Gestão, Dimensionamento de Pessoal e Equipe Multiprofissional e Condições de trabalho. Quanto aos facilitadores e sugestões foram apontados Relacionamento interpessoal, Capacitação, Participação da gestão $e$ Restruturação do serviço. Diante do exposto é possível concluir que para que ocorra o cuidado humanizado nos serviços de urgência/emergência é necessária uma abordagem multifatorial, a fim de erradicar ou ao menos atenuar os entraves apresentados.

Palavras chave: Humanização da Assistência; Emergências; Acolhimento. 


\section{Introdução}

O interesse pela qualidade do serviço em saúde é mundial e esteve presente ao longo da história da humanidade ${ }^{1}$. No Brasil, um marco para a melhoria da qualidade do serviço em saúde foi a Constituição Federal de 1988, que trouxe a saúde como direito de todos e dever do estado, possibilitando a criação do Sistema Único de Saúde (SUS) mediante a Lei 8080/90².

Um dos meios de qualificação do serviço de saúde é a humanização. Existem duas vertentes para a compreensão do conceito: humanização no sentido da valorização do indivíduo, de sorriso no rosto, de chamar o paciente pelo nome, tratar com respeito, levando em conta a sua subjetividade e individualidade; e a humanização no sentido de reorganização do processo de trabalho, em busca da melhoria da qualidade do atendimento além dos sentidos humanos ${ }^{2,3}$.

Dessa forma, com o objetivo de reafirmar a proposta estabelecida no surgimento do SUS, foram delineadas estratégias governamentais para a valorização do usuário e resolução dos seus problemas. No ano 2000, o Ministério da Saúde promulgou o Programa Nacional de Humanização da Atenção Hospitalar (PNHAH), trazendo a humanização para o ambiente hospitalar ${ }^{2}$.

A PNHAH veio como um novo desafio para o SUS. Em busca da melhoria da qualidade dos serviços hospitalares brasileiros através da reestruturação de serviços e estratégias, visa a melhoria da relação profissional-usuário e o incentivo a dimensão humana e subjetiva da assistência, para que assim ocorra uma melhor qualidade da assistência prestada ${ }^{4}$. O programa objetiva o respeito, a solidariedade e o desenvolvimento da autonomia e da cidadania dos profissionais da Saúde e dos usuários ${ }^{5}$.

Em 2003, o Ministério da Saúde ampliou o conceito de humanização para todos os níveis de atenção em saúde através da Política Nacional de Humanização a atenção e da gestão (PNH). Essa política fortaleceu o SUS como política de saúde, por ter como base seus princípios de igualdade, universalidade, equidade e participação social ${ }^{6}$. Na PNH a humanização deve perpassar por todos os setores e por todos os serviços, porém, na prática, é na atenção terciária onde ela encontra maior dificuldade, pela alta complexidade dos serviços e pelo trabalho voltado as tecnologias duras ${ }^{7}$.

O serviço de urgência/emergência hospitalar funciona $24 \mathrm{~h}$ por dia, e atende situações de natureza clínica, traumática e psiquiátrica de caráter imediato. Possui alta rotatividade de pessoas e rotina acelerada que colocam todos os envolvidos nesse processo em estado de estresse e angustia da vida e da morte 8 .

Dada a complexidade desses serviço e a necessidade de estar em consonância com os princípios do SUS, a PNH traz o Acolhimento Com Classificação de Risco (ACCR) como uma ferramenta para avaliar e classificar os riscos dos usuários segundo a necessidade de tratamento imediato, o potencial de risco, agravos à saúde ou grau de sofrimento, afim de modificar o processo de trabalho e produzir saúde, diminuído filas e melhorando o atendimento ${ }^{6,9}$.

O ACCR é uma diretriz operacional que funciona como um instrumento-chave para melhoria do atendimento ao usuário pela modificação do fluxo de trabalho, garantindo humanização da assistência, atendimento mais acolhedor e menos excludente. Ele acontece por meio de uma consulta de enfermagem onde o enfermeiro de acordo com os sinais e sintomas apresentados pelo usuário e utilizando um protocolo vai classifica-lo e estipular o tempo médio para o atendimento médico ${ }^{10}$.

O enfermeiro, pela sua práxis de gerência e liderança da equipe de enfermagem, são os que passam a maior parte do tempo em contato com os pacientes. Desta forma, eles têm a responsabilidade pela organização do processo de trabalho, a capacitação e treinamento da sua equipe, de forma que atenda demandas da $\mathrm{PNH}^{2}$. Porém, esses serviços enfrentam dificuldades para efetivar o cuidado humanizado devido aos problemas e sobrecargas presentes em sua prática diária ${ }^{11}$.

Deste modo, essa pesquisa justifica-se pela necessidade de problematização da micropolítica do processo de trabalho para identificar os bloqueios na melhoria da atenção prestada no serviço de emergência, como base na $\mathrm{PNH}$. Considerando o papel do enfermeiro na organização dos serviços em saúde e necessidade da implementação da humanização no serviço de emergência, pergunta-se: quais as facilidades e os entraves para implementação do processo de humanização na emergência? Esse trabalho tem como objetivo identificar na produção científica relacionada ao cuidado humanizado nos serviços de urgência/emergência quais os entraves e facilidades para o cuidado humanizado nesses serviços.

\section{Metodologia}

Trata-se de uma pesquisa bibliográfica do tipo revisão integrativa de literatura, sobre os 
entraves e facilidades do cuidado humanizado nos serviços de urgência/emergência. O estudo consiste em um Trabalho de Conclusão de Curso de Graduação, do curso de Enfermagem da Universidade Estadual de Santa Cruz.

A revisão de literatura é todo o processo de busca do referencial teórico de um determinado assunto, fazendo sua análise e descrição, visando o esclarecimento das questões norteadoras. 0 nome literatura faz com que abarque qualquer escrito científico sobre o tema, podendo utilizar livros, artigos, periódicos, teses, dissertações, registros históricos e governamentais ${ }^{12}$.

Esse tipo de pesquisa abrange a revisão narrativa, revisão sistemática e revisão integrativa, que são diferenciadas pelo método utilizado na sua elaboração. A revisão integrativa é um estudo abrangente que permite a inclusão de pesquisas experimentais e não experimentais para o amplo entendimento do tema. Para sua elaboração é necessário formular uma pergunta norteadora, realizar a busca ou amostragem literária, coletar os dados, analisar de forma crítica os estudos incluídos, fazer a discussão dos resultados e apresentar o resumo do conteúdo encontrado, concluindo suas seis etapas ${ }^{13}$.

Como fonte de dados para esta pesquisa utilizou-se artigos científicos. Os artigos foram selecionados, no período de abril e maio de 2018, por meio de busca bibliográfica na Biblioteca Virtual em Saúde (BVS). A BVS é uma plataforma operacional de cooperação técnica da Organização Pan-Americana da Saúde (OPAS), que oferece acesso a um acervo que abrande diversos bancos de dados como LILACS, SCIELO, BDENF, MEDLINE entre outros.

Utilizou-se como critérios de inclusão: artigos completos indexados na BVS independente do banco de dados, publicados em português, nos últimos cinco anos (2013-2017), que estivessem disponíveis para leitura, e que atendessem aos objetivos do estudo. Quanto aos critérios de exclusão delimitou-se: estudos que não abordassem os objetivos propostos, que tivessem como temática serviços de emergência pré-hospitalar móvel e serviços de emergência pediátrica, artigos duplicados e que não atendessem aos critérios de inclusão.

$\mathrm{Na}$ busca bibliográfica nas bases de dados da BVS foi utilizado os seguintes descritores: humanização da assistência; emergências; acolhimento; humanização da assistência AND emergências; e humanização da assistência AND emergências AND acolhimento. Com o descritor "humanização da assistência" foram encontrados 3.681 resultados, sendo selecionados 8 artigos. Utilizando o descritor "emergência" 143.810 resultados foram obtidos, foi selecionada 1 artigos; usando os descritores "humanização da assistência AND emergências" foram obtidos 94 artigos, 1 artigo foi selecionado; com o descritor "acolhimento" 3.523 resultados foram encontrados e 3 artigos selecionados; como os descritores "humanização da assistência AND emergências AND acolhimento" foi encontrado 42 artigos e nenhum foi selecionado. Totalizando 13 artigos. Os artigos foram selecionados após leitura e aplicação dos critérios de inclusão exclusão supracitados. A etapa seguinte consistiu na análise dos dados feita a partir de leituras, fichamentos e elaboração de síntese do material levantado.

\section{Resultados e Discussões}

Com base na metodologia forma analisados 13 artigos. No Quadro 1 estão apresentados o sumário das características dos estudos incluídos, os artigos foram nomeados de A1 à A13 por ordem alfabética de seus títulos.

Quadro 1. Caracterização dos artigos organizados por título, autores, periódicos e delineamento do estudo.

\begin{tabular}{|c|c|c|c|c|c|}
\hline Artigos & $\begin{array}{l}\text { Base de } \\
\text { Dados }\end{array}$ & Título do artigo & Autores & $\begin{array}{l}\text { Periódico (vol, no, } \\
\text { pág, ano) }\end{array}$ & Resultados \\
\hline $\mathrm{A} 1$ & SCIELO & 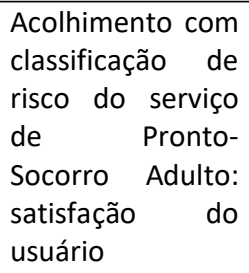 & $\begin{array}{lll}\text { SILVA, P. } & \text { L.; } \\
\text { PAIVA, } & \text { L.; } \\
\text { FARIA, V. } & \text { R.; } \\
\text { OHL, R. I. } & \text { B.; } \\
\text { CHAVAGLIA, } \\
\text { S.R.R. }\end{array}$ & $\begin{array}{l}\text { Revista da Escola de } \\
\text { Enfermagem da } \\
\text { USP . 2016; v. 50, n. } \\
3 \text {, p. 427-433 }\end{array}$ & $\begin{array}{l}\text { Entraves: estrutura física. } \\
\text { Facilidades: Postura } \\
\text { Profissional } \\
\text { Relacionamento } \\
\text { interpessoal. } \\
\text { Sugestões: Restruturação } \\
\text { do serviço }\end{array}$ \\
\hline
\end{tabular}

Continua... 


\begin{tabular}{|c|c|c|c|c|c|}
\hline $\mathrm{A} 2$ & LILACS & $\begin{array}{l}\text { Acolhimento com } \\
\text { classificação de } \\
\text { risco em serviço } \\
\text { hospitalar de } \\
\text { emergência: } \\
\text { avaliação do } \\
\text { processo de } \\
\text { atendimento }\end{array}$ & $\begin{array}{l}\text { BELLUCI, J.A.J.; } \\
\text { VITURI, D.W.; } \\
\text { VERSA, } \\
\text { G.L.G.S.; } \\
\text { FURUYA, P. S.; } \\
\text { VIDOR, R.C.; } \\
\text { MATSUDA, L. } \\
\text { M }\end{array}$ & $\begin{array}{c}\text { Revista de } \\
\text { enfermagem da } \\
\text { UERJ, Rio de } \\
\text { Janeiro, } 2015 \\
\text { jan/fev; v. } 23, \text { n. } 1 . \\
\text { p. } 82-7\end{array}$ & $\begin{array}{l}\text { Entraves: estrutura física; } \\
\text { recursos materiais; } \\
\text { condições de trabalho; } \\
\text { gestão; fluxo invertido; } \\
\text { dimensionamento de } \\
\text { pessoal; equipe } \\
\text { multiprofissional. } \\
\text { Facilidades: não } \\
\text { apresentou. } \\
\text { Sugestões: capacitação; } \\
\text { participação da gestão. }\end{array}$ \\
\hline A3 & LILACS & $\begin{array}{c}\text { Acolhimento } \\
\text { Com Classificação } \\
\text { de Risco: } \\
\text { Avaliação da } \\
\text { Estrutura, } \\
\text { Processo e } \\
\text { Resultado }\end{array}$ & $\begin{array}{l}\text { INOUE, K.C.; } \\
\text { MURASSAKI, } \\
\text { A.C.Y.; } \\
\text { BELUCCI, J.A.J.; } \\
\text { ROSSI, R. M.; } \\
\text { MARTINEZ, Y. } \\
\text { D.E.; } \\
\text { MATSUDA, } \\
\text { L.M. }\end{array}$ & $\begin{array}{c}\text { Revista Mineira de } \\
\text { Enfermagem } 2015 \\
\text { jan/mar; v. } 19, \text { n. } 1 \text {, } \\
\text { p. } 13-20\end{array}$ & $\begin{array}{c}\text { Entraves: Superlotação; } \\
\text { estrutura física; recursos } \\
\text { materiais; conhecimento } \\
\text { limitado do usuário; fluxo } \\
\text { invertido; equipe } \\
\text { multiprofissional. } \\
\text { Facilidades: não } \\
\text { apresentou. } \\
\text { Sugestões: capacitação; } \\
\text { participação da gestão; } \\
\text { Restruturação do serviço. }\end{array}$ \\
\hline A4 & LILACS & $\begin{array}{l}\text { Acolhimento com } \\
\text { Classificação de } \\
\text { Risco: Avaliação } \\
\text { de Serviços } \\
\text { Hospitalares de } \\
\text { Emergência }\end{array}$ & $\begin{array}{l}\text { COSTA, M.A.R.; } \\
\text { VERSA, } \\
\text { G.L.G.S.; } \\
\text { BELLUCCI, J.A.; } \\
\text { INOUE, K.C.; } \\
\text { SALES, C.A.; } \\
\text { MATSUDA, } \\
\text { L.M. }\end{array}$ & $\begin{array}{c}\text { Escola Anna Nery, } \\
\text { v.19, n. 3, p. 491- } \\
497,2015\end{array}$ & $\begin{array}{c}\text { Entraves: Superlotação; } \\
\text { condições de trabalho; } \\
\text { conhecimento limitado } \\
\text { do usuário; } \\
\text { dimensionamento de } \\
\text { pessoal; } \\
\text { Facilidades: não } \\
\text { apresentou. } \\
\text { Sugestões: capacitação; } \\
\text { participação da gestão; } \\
\text { Restruturação do serviço }\end{array}$ \\
\hline A5 & LILACS & $\begin{array}{c}\text { Acolhimento } \\
\text { como estratégia } \\
\text { para alcançar a } \\
\text { integralidade da } \\
\text { assistência em } \\
\text { hospital de média } \\
\text { complexidade }\end{array}$ & $\begin{array}{c}\text { GOULART, } \\
\text { C.B.; HADDAD, } \\
\text { C.L.; } \\
\text { VANNUCHI, } \\
\text { M.T.O.; } \\
\text { ROSSANEIS, M. } \\
\text { A. R. }\end{array}$ & $\begin{array}{l}\text { Semina: Ciências } \\
\text { Biológicas e da } \\
\text { Saúde, Londrina, v. } \\
\text { 34, n. 1, p. 91-96, } \\
\text { jan./jul. } 2013\end{array}$ & $\begin{array}{c}\text { Entraves: Superlotação; } \\
\text { estrutura física; recursos } \\
\text { materiais; condições de } \\
\text { trabalho; gestão; fluxo } \\
\text { invertido; } \\
\text { dimensionamento de } \\
\text { pessoal; } \\
\text { Facilidades: não } \\
\text { apresentou. } \\
\text { Sugestões: Postura } \\
\text { Profissional e } \\
\text { Relacionamento } \\
\text { interpessoal; } \\
\text { capacitação. }\end{array}$ \\
\hline A6 & LILACS & $\begin{array}{l}\text { Acolhimento e } \\
\text { Humanização da } \\
\text { Assistência em } \\
\text { Pronto-Socorro } \\
\text { Adulto: } \\
\text { Pcrccpções de } \\
\text { Enfermeiros }\end{array}$ & $\begin{array}{l}\text { LIMA, A.V.N.; } \\
\text { NUNES, V. M. } \\
\text { A.; } \\
\text { FERNANDES, R. } \\
\text { L.; BARBOSA, I. } \\
\text { M. L.; } \\
\text { CARVALHO, G. } \\
\text { R. P. }\end{array}$ & $\begin{array}{c}\text { Revista de } \\
\text { Enfermagem da } \\
\text { UFSM } 2013 \\
\text { Mai/Ago; v. 3, n. 2, } \\
\text { p. } 276-286\end{array}$ & $\begin{array}{c}\text { Entraves: Superlotação; } \\
\text { estrutura física; recursos } \\
\text { materiais; condições de } \\
\text { trabalho; fluxo invertido; } \\
\text { dimensionamento de } \\
\text { pessoal. } \\
\text { Facilidades: Postura } \\
\text { Profissional e } \\
\text { Relacionamento } \\
\text { interpessoal. } \\
\text { Sugestões: capacitação; } \\
\text { participação da gestão. }\end{array}$ \\
\hline
\end{tabular}

Continua... 


\begin{tabular}{|c|c|c|c|c|c|}
\hline A7 & LILACS & $\begin{array}{c}\text { Entraves no } \\
\text { Acolhimento por } \\
\text { Enfermeiros de } \\
\text { um Hospital } \\
\text { Público }\end{array}$ & $\begin{array}{l}\text { GRIMBERG, } \\
\text { S.K.C.R.; } \\
\text { SOUSA, E.F; } \\
\text { ASSIS, C.M. L.; } \\
\text { GUIMARÃES, } \\
\text { D.A.; } \\
\text { NOBREGA, J. A. } \\
\text { S. }\end{array}$ & $\begin{array}{l}\text { Revista Brasileira de } \\
\text { Ciências da Saúde } \\
\text { v.19, n.4, p. 299- } \\
\text { 306, } 2015\end{array}$ & $\begin{array}{c}\text { Entraves: Superlotação; } \\
\text { estrutura física; recursos } \\
\text { materiais; condições de } \\
\text { trabalho; } \\
\text { dimensionamento de } \\
\text { pessoal; equipe } \\
\text { multiprofissional. } \\
\text { Facilidades: não } \\
\text { apresentou. } \\
\text { Sugestões: capacitação; }\end{array}$ \\
\hline A8 & BDENF & $\begin{array}{l}\text { Experiências } \\
\text { Cotidianas do } \\
\text { Enfermeiro na } \\
\text { Classificação de } \\
\text { Risco em } \\
\text { Unidade de } \\
\text { Pronto } \\
\text { Atendimento }\end{array}$ & $\begin{array}{l}\text { ROCALLI, A.A.; } \\
\text { OLIVEIRA, D.N; } \\
\text { MELO, I. C; } \\
\text { VIEGAS, S.M.F; } \\
\text { BRITO, R. F. }\end{array}$ & $\begin{array}{c}\text { Revista de } \\
\text { enfermagem da } \\
\text { UFPE on line., } \\
\text { Recife, v. 11, n. 4, p. } \\
\text { 1743-51, abr., } \\
2017 a\end{array}$ & $\begin{array}{l}\text { Entraves: Superlotação; } \\
\text { estrutura física; } \\
\text { condições de trabalho; } \\
\text { conhecimento limitado } \\
\text { do usuário; fluxo } \\
\text { invertido; } \\
\text { Facilidades: não } \\
\text { apresentou. } \\
\text { Sugestões: capacitação. }\end{array}$ \\
\hline A9 & LILACS & $\begin{array}{l}\text { Humanização da } \\
\text { Assistência em } \\
\text { Atendimento de } \\
\text { Urgência } \\
\text { Hospitalar: } \\
\text { Percepção dos } \\
\text { Enfermeiros }\end{array}$ & $\begin{array}{l}\text { CAVALCANTE, } \\
\text { A.K.C.B.; } \\
\text { DAMASCENO, } \\
\text { C. A. F.; } \\
\text { MIRANDA, M. } \\
\text { D. S. }\end{array}$ & $\begin{array}{c}\text { Revista Baiana de } \\
\text { Enfermagem, } \\
\text { Salvador, v. } 27, \text { n. } 3 \text {, } \\
\text { p. } 221-233, \\
\text { set./dez. } 2013\end{array}$ & $\begin{array}{l}\text { Entraves: Superlotação; } \\
\text { estrutura física; recursos } \\
\text { materiais; condições de } \\
\text { trabalho; } \\
\text { dimensionamento de } \\
\text { pessoal; equipe } \\
\text { multiprofissional. } \\
\text { Facilidades: não } \\
\text { apresentou. } \\
\text { Sugestões: Postura } \\
\text { Profissional e } \\
\text { Relacionamento } \\
\text { interpessoal; } \\
\text { capacitação; } \\
\text { Restruturação do serviço }\end{array}$ \\
\hline A10 & BDENF & $\begin{array}{c}\text { Opinião De } \\
\text { Enfermeiros } \\
\text { Sobre } \\
\text { Classificação De } \\
\text { Risco Em Serviços } \\
\text { De Urgência }\end{array}$ & $\begin{array}{l}\text { DURO, C.L.M.; } \\
\text { LIMA, M. A. } \\
\text { D.S.; WEBER; } \\
\text { L.A.F. }\end{array}$ & $\begin{array}{l}\text { Revista Mineira de } \\
\text { Enfermagem, v. 21, } \\
\text { p. } 1062-1070,2017\end{array}$ & $\begin{array}{l}\text { Entraves: Superlotação; } \\
\text { condições de trabalho; } \\
\text { estrutura física; } \\
\text { conhecimento limitado } \\
\text { do usuário; fluxo } \\
\text { invertido; } \\
\text { dimensionamento de } \\
\text { pessoal; } \\
\text { Facilidades: não } \\
\text { apresentou. } \\
\text { Sugestões: capacitação; }\end{array}$ \\
\hline A11 & BDENF & $\begin{array}{c}\text { Percepção de } \\
\text { Enfermeira(o)s } \\
\text { Sobre } \\
\text { Acolhimento } \\
\text { Com Classificação } \\
\text { de Risco no } \\
\text { Serviço de Pronto } \\
\text { Atendimento }\end{array}$ & $\begin{array}{l}\text { PRUDÊNCIO, } \\
\text { C.P.G; } \\
\text { MONTEIRO, } \\
\text { R.A.N.; } \\
\text { RIBEIRO, } \\
\text { B.C.M.R.; } \\
\text { GOMES, M. } \\
\text { S.M.; } \\
\text { MAGALHÃES, } \\
\text { L. S.P. }\end{array}$ & $\begin{array}{l}\text { Revista Baiana de } \\
\text { Enfermagem, } \\
\text { Salvador, v. 30, n. 2, } \\
\text { p. 1-10, abr./jun. } \\
2016\end{array}$ & $\begin{array}{l}\text { Entraves: Superlotação; } \\
\text { estrutura física; recursos } \\
\text { materiais; condições de } \\
\text { trabalho; gestão; } \\
\text { conhecimento limitado } \\
\text { do usuário; fluxo } \\
\text { invertido; } \\
\text { dimensionamento de } \\
\text { pessoal; } \\
\text { Facilidades: não } \\
\text { apresentou. } \\
\text { Sugestões: capacitação; } \\
\text { Restruturação do serviço }\end{array}$ \\
\hline
\end{tabular}

Continua... 


\begin{tabular}{|c|c|c|c|c|c|}
\hline A12 & LILACS & $\begin{array}{l}\text { Percepção de } \\
\text { médicos e } \\
\text { enfermeiros de } \\
\text { unidades de } \\
\text { assistência } \\
\text { médica } \\
\text { ambulatorial } \\
\text { sobre } \\
\text { humanização nos } \\
\text { serviços de saúde }\end{array}$ & $\begin{array}{l}\text { SEOANE, A.F.; } \\
\text { FORTES, P.A.C. }\end{array}$ & $\begin{array}{c}\text { Saúde e Sociedade, } \\
\text { v.23, n.4, p.1408- } \\
1416,2014\end{array}$ & $\begin{array}{c}\text { Entraves: não } \\
\text { apresentou. } \\
\text { Facilidades: não } \\
\text { apresentou. } \\
\text { Sugestões: Postura } \\
\text { Profissional e } \\
\text { Relacionamento } \\
\text { interpessoal; } \\
\text { capacitação; } \\
\text { Restruturação do serviço }\end{array}$ \\
\hline A13 & LILACS & $\begin{array}{l}\text { Protocolo De } \\
\text { Manchester E } \\
\text { População } \\
\text { Usuária Na } \\
\text { Classificação De } \\
\text { Risco: Visão Do } \\
\text { Enfermeiro }\end{array}$ & $\begin{array}{l}\text { RONCALLI, A. } \\
\text { A.; OLIVEIRA, } \\
\text { D.N.; SILVA, } \\
\text { I.C.M; BRITO, } \\
\text { R.F.; VIEGAS, } \\
\text { S.M.F. }\end{array}$ & $\begin{array}{l}\text { Revista Baiana de } \\
\text { Enfermagem, } \\
\text { Salvador, v.31, n.2, } \\
\text { p. } 1-10 b, 2017\end{array}$ & $\begin{array}{l}\text { Entraves: Superlotação; } \\
\text { condições de trabalho; } \\
\text { conhecimento limitado } \\
\text { do usuário; fluxo } \\
\text { invertido; equipe } \\
\text { multiprofissional. } \\
\text { Facilidades: não } \\
\text { apresentou. } \\
\text { Sugestões: capacitação; }\end{array}$ \\
\hline
\end{tabular}

Fonte: elaborado pela autora, 2018

A partir dos 13 artigos selecionados foi possível dividir os resultados em duas categorias, sendo 5 subcategorias na primeira categoria e 3 subcategorias na segunda categoria, de acordo com os objetivos propostos e o conteúdo apresentado na pesquisa. A partir da análise dos artigos inseridos foi possível identificar os seguintes entraves e facilidades e sugestões.

Entraves para o cuidado humanizado nos serviços de urgência/emergência

Superlotação, Fluxo invertido e Conhecimento limitado do usuário

A superlotação foi um dos entraves mais citados nos artigos pesquisados, 10 dos 13 artigos. Esse entrave dificulta o atendimento pois a demanda excessiva tumultua o processo de trabalho, sobrecarrega os profissionais e o serviço e dificulta o acesso das pessoas que realmente necessitam de atendimento ${ }^{14,15}$. Os autores que citem esse entrave, não fazem a relação direta entre a superlotação e o funcionamento inadequado da atenção básica, porém usuários que não conseguem atendimento nesse nível de atenção, procuram as urgência e emergência em busca de atendimento rápido e resolutivo, transformando esse setor na porta de entrada para o serviço de saúde ${ }^{16,17} .0$ funcionamento inadequado do serviço de atenção básica esteve presente em 8 dos 13 artigos incluídos, para esses autores, sempre relacionado com o principal fator causador da superlotação. O Mistério da Saúde investe em políticas que fortalecem a atenção básica, investindo na prevenção e promoção de saúde, bem como na resolução de caso não graves a nível primário. Porém a falta de estrutura que acomete muitos municípios, faz com que o pronto-atendimento seja a porta de entrada para os serviços de saúde sobrecarregando esses setores, gerando o Fluxo invertido ${ }^{9}$.

Por conta da cobertura inadequada da Estratégia de Saúde da Família, deficiências da atenção primária à saúde como: demora para o agendamento de consultas, horário restrito de funcionamento, acesso reduzido a medicações, e a baixa resolutividade, além da ausência de referência e contra referência ${ }^{14,18}$, a população (demanda reprimida) recorre aos serviços de urgência/emergências devido a garantia de atendimento, acesso mais ágil e fácil a consultas, exames e diagnósticos, tornando esses serviços referências para a população e com isso, acabam caracterizados pela superlotação, tratamento impessoal e por atuarem apenas na queixa principal do usuário ${ }^{10}$.

Além disso, seis artigos apontaram o conhecimento limitado do usuário acerca do funcionamento e finalidade do serviço de emergência como um entrave para o cuidado humanizado. Roncalli et al $^{17}$ traz que esses usuários com o conhecimento limitado e provindos da demanda reprimida interferem na dinâmica do serviço, pois casos não urgentes procuram o serviço e reivindicam atendimento 
rápido e resolutivo que deveria ser realizado em outros níveis de atenção. Por não entenderem o processo ou por não ter recebido a resposta esperada, muitos questionam a dinâmica de atendimento e descontam suas frustações nos profissionais, em especial na equipe de enfermagem que são os profissionais mais próximos a eles ${ }^{17,18}$.

O contexto acima descrito favorece a ocorrência de um problema tido como grave e que foi citado por dois dos artigos analisados: a violência ocupacional. Esta acontece quando usuários insatisfeitos com a situação do serviço, se tornam hostis agridem os profissionais de forma verbal e até mesmo física ${ }^{19}$. Dessa forma, esses Três entraves apresentam uma relação de causa e consequência, onde o conhecimento limitado dos usuários leva a um fluxo invertido e consequentemente a superlotação.

\section{Estrutura física e recursos materiais}

Esses são entraves citados em dez e sete artigos respectivamente, onde os autores abordam a limitação de se prestar cuidado humanizado de qualidade com recursos e estrutura física limitados ${ }^{18}$. A PNH estabelece que para o cuidado humanizado é necessário ter estrutura. Os autores discorrem que nos serviços pesquisados há carência de uma estrutura adequada destinado para receber, acolher, alocar e atender a quantidade de paciente e seus acompanhantes, questão garantida na referida política ${ }^{14}$. Ademais, recursos matérias insuficientes também dificultam a prestação de serviços em sua totalidade, gerando um cuidado limitado, levando ao improviso que pode ser fator desencadeador de iatrogenias ${ }^{9}$.

\section{Dimensionamentos de Pessoal e Equipe Multiprofissional}

Oito artigos trazem o dimensionamento de pessoal e cinco artigos trazem a equipe multiprofissional como entraves para a humanização. A falta de profissionais reflete diretamente na assistência prestada. 0 dimensionamento incorreto sobrecarrega os profissionais em serviço, diminui o tempo para prestar o cuidado para cada usuário, acarretando no cuidado fragilizado e superficial ${ }^{19}$. Os profissionais que atuam no âmbito da saúde transformam a realidade do usuário do serviço uma vez que identificam e contribuem para a solução do problema que o usuário traz consigo e, portanto, a deficiência no número de profissionais reflete diretamente na qualidade do atendimento ${ }^{18}$.

A multiprofissionalidade se faz importante no atendimento, visto que possibilita um atendimento especializado à necessidade apresentada pelo usuário. Porém a equipe que poderia ser solução, se torna um entrave quando os profissionais não trabalham em conjunto, sem comunicação efetiva, sem ética profissional e desconhecimento de todo o processo de trabalho. Tais posturas geram questionamentos desnecessários e indevidos sobre o trabalho dos outros profissionais da equipe, aumentando o desgaste no ambiente de trabalho ${ }^{15,19}$.

\section{Gestão}

Apenas três artigos trazem a participação limitada da gestão como um entrave para o cuidado humanizado. Belluci et $\mathrm{al}^{20}$ aponta que os entraves da emergência são de difícil resolução, pois requerem alto investimento financeiro, grande esforço dos gestores e trabalhadores e empenho dos usuários em compreender os processos que envolvem a rede de atenção à saúde. Muitos dos entraves supracitados requerem participação ativa e resolutiva por parte dos gestores de saúde nos diversos níveis de poder, além da discussão sobre o processo e as condições de trabalho a nível do serviço com os demais autores que compõe o cenário da assistência ${ }^{18,20}$. Porém em apenas três estudos foi reconhecido a participação da gestão como parte do problema.

\section{Condições de trabalho}

Nove dos artigos pesquisados abordam as condições de trabalho com um entrave para o cuidado. Todos os problemas supracitados possuem relação com esse entrave, considerando o ambiente naturalmente estressante da emergência somado às longas e múltiplas jornadas de trabalho, ocorre a sobrecarga desses trabalhadores, gerando desgaste físico, metal e emocional com consequente adoecimento e culminando numa assistência fragilizada. Logo ocorre uma interferência negativa no tratar desse profissional ao usuário ${ }^{2,21}$. Torna-se difícil humanizar quando o profissional não é tradado de forma humanizada ${ }^{19}$.

Nenhum dos artigos citou a síndrome de Burnout ou Síndrome do Estresse Profissional, que é desencadeada pelo estresse crônico no ambiente de trabalho. Contudo é relevante discuti-la, pois, o ambiente estressante inerente a realidade do trabalhador da saúde, sobretudo 
enfermeiros, mostra uma enorme vulnerabilidade para que estes desenvolvam doenças ocupacionais como a referida síndrome. Esta se desenvolve de forma gradual, dificultando sua detecção precoce, e por consequência gerando impacto na vida do profissional e por conseguinte na assistência prestada ${ }^{22}$.

\section{Facilidades e Sugestões para o cuidado Humanizado}

Dos artigos pesquisados apenas dois trazem quais características da emergência facilitaria o cuidado humanizado os demais artigos oferecem sugestões.

Postura Profissional e Relacionamento interpessoal

A postura profissional referente ao relacionamento com o usuário foi a única facilidade apontada em dois artigos. Na pesquisa realizada por Silva et al $^{10}$ com usuários de um serviço de saúde, a postura profissional demonstrada na forma de tratar o paciente e seus familiares, de oferecer informações claras e objetivas e demostrar que se importa, foi muito bem avaliado pelos usuários como uma forma de cuidado humanizado.

Três outros artigos trazem o relacionamento interpessoal como uma sugestão para o cuidado humanizado. Não apenas o relacionamento entre o profissional e o usuário, já supracitado, como também o relacionamento entre os profissionais da equipe de saúde. Pois se os profissionais vivem em um ambiente humanizado, naturalmente vão conseguir humanizar a assistência. A equipe multiprofissional conseguindo trabalhar de forma conjunta, respeitosa e ética, consegue ampliar essa postura para o usuário, prestando um cuidado mais amplo e de qualidade, melhorando a relação usuário-profissional ${ }^{23}$.

\section{Capacitação}

A capacitação dos profissionais foi uma sugestão que não apareceu em apenas um estudo. O único artigo que não abordou essa temática foi um estudo que mostrou a visão dos usuários sobre a humanização da assistência ${ }^{10}$, todos os demais destacaram a importância de capacitar os profissionais tanto para o serviço prestado na emergência, como para a humanização. A educação permanente se faz necessária, pois a área da saúde é campo que está em constante evolução, exigindo dos profissionais atualização constante. $\mathrm{Na}$ emergência por ser um setor que demanda decisões rápidas e precisas, quanto maior o conhecimento do profissional, mais confiável a classificação e atendimento realizado ${ }^{19}$.

\section{Participação da gestão e Restruturação do serviço}

Quatro artigos citam a participação da gestão como fator importante para o cuidado humanizado. As pesquisas sugerem a implementação de ações gerenciais junto a equipe a fim de fortalecer o protagonismo dos atores envolvidos e efetivar a humanização do atendimento, com uma postura de aproximação e responsabilização, oferecendo compromisso e confiança a profissionais e usuários ${ }^{9,14}$. O que faz parte da restaurações dos serviços. Seis artigos trazem a restruturação do serviço como fator que contribui para a humanização. Reestruturar envolve melhoria das condições de trabalho, dimensionamento de pessoal adequado, valorização dos profissionais, participação de todos nas soluções, reorganização de fluxos e repactuação do processo de trabalho, de maneira prática, técnico e administrativa, para que a partir disso o profissional tenha subsidio para humanizar ${ }^{18,19}$.

\section{Conclusão}

Houve avanços no que diz respeito a políticas públicas que visam a humanização do atendimento e qualificação do serviço de saúde nos diversos níveis de atenção, porém esses avanços teóricos se desencontram na pratica cotidiana. $\mathrm{Na}$ pesquisa realizada foi possível identificar uma série de entraves à humanização, como a superlotação, a estrutura física inadequada, os recursos materiais insuficientes, o fluxo invertido, o conhecimento insuficiente por parte da população, o dimensionamento de pessoal equivocado, o trabalho fragmentado, as condições de trabalho inadequadas e a gestão não participativa.

Como facilidade apenas foi identificado a postura profissional, o que mostra a importância do enfermeiro como agente transformador da realidade do paciente, valorização das suas necessidades e de todos os níveis do "ser". Com isso é importante refletir sobre a satisfação profissional dos trabalhadores, oferecer reconhecimento, respeito, ambiente e condições de trabalho adequados. Para que ocorra humanização é necessário investimento na formação humana do profissional, reconhecer seus limites, valorizar os fatores que envolvem sua dimensão humana, incentivar sua autonomia, justiça e dignidade. 
A postura profissional também foi citada como sugestão para a humanização, junto com a capacitação profissional, restruturação do serviço e participação da gestão. Tais achados demonstram a complexidade para a resolução desses entraves. Apesar dos autores dos estudos abordados citarem a importância da intervenção da gestão, o foco de suas conclusões e sugestões estava no relacionamento interpessoal entre profissionais e usuários. Entretanto, muitos dos entraves elencados estão fora da governabilidade dos profissionais, sendo fundamental a participação da gestão nesse processo.

\section{Referências}

1. Carvalho G. A saúde pública no Brasil. Estudos Avançados. 2013;27(78):7-26.Disponível em:

http://www.scielo.br/scielo.php?script=sci_artte $\mathrm{xt} \& \mathrm{pid}=\mathrm{S0103}$ 40142013000200002\&lng=pt\&tlng=pt

2. Grimberg S, Sousa E, Assis C, Guimarães D, Nóbrega J. Entraves no Acolhimento por Enfermeiros de um Hospital Público. Rev Bras Ciências da Saúde [Internet]. 2015;19(4):299-306. Disponível em: http://periodicos.ufpb.br/ojs/index.php/rbcs/arti cle/view/19857/15105

3. Morais AMS. A humanização na área na saúde: uma proposta reflexiva para o Serviço Social. Dissertação (Mestrado) - Pontifícia Universidade Católica de Goiás. 2016. p. 94.; Disponível em: http://tede2.pucgoias.edu.br:8080/bitstream/te de/3552/2/ANA\%20MARIA\%20SANTANA\%20MO RAIS.pdf

4. Barbosa GC, Meneguim S, Lima SAM, Moreno V. Política Nacional de Humanização e formação dos profissionais de saúde: revisão integrativa. Rev Bras Enferm [Internet]. 2013;66(1):123-7.:

http://www.scielo.br/pdf/reben/v66n1/v66n1a1 9.pdf

5. Ministério da Saúde. Programa nacional de humanização da assistência hospitalar. Série C Proj Programas e Relatórios, n 20. 2001;1-60. Disponível em: http://bvsms.saude.gov.br/bvs/publicacoes/pnha h01.pdf

6. Ministério da Saúde. Política Nacional de Humanização. Ministério Da Saúde Do Bras. 2013;16. Disponível em: http://bvsms.saude.gov.br/bvs/publicacoes/polit ica_nacional_humanizacao_pnh_folheto.pdf 7. Duarte MLC, Noro A. Humanização do atendimento no setor de radiologia : dificuldades e sugestões dos profissionais de enfermagem. Cogitare Enferm. 2013;18(3):532-8. Disponível em:

https://revistas.ufpr.br/cogitare/article/view/335 $68 / 21066$

8. Camerro A, Alves EC, Moraes N, Donizete L, Nogueira P. Perfil do atendimento de serviços de urgência e emergência. Rev Fafibe On-Line. 2015;2(1):515-24. Disponível em: http://unifafibe.com.br/revistasonline/arquivos/r evistafafibeonline/sumario/36/10112015195658. pdf

9. Lima, A.; Nunes V., Fernandes R., Barbosa, I.; Carvalho G. Humanização e acolhimento em emergência hospitalar: fatores condicionantes sob o olhar dos enfermeiros. Rev Pesqui Cuid é Fundam Online [Internet]. 2013;5(4):519-28. Disponível em: http://seer.unirio.br/index.php/cuidadofundame ntal/article/view/2619/pdf_926

10. Silva PL, Paiva L, Faria VB, Isabel R, Ohl B, Regina $S$, et al. Acolhimento com classificação de risco do serviço de Pronto-Socorro Adulto: satisfação do usuário. Rev da Esc ola Enferm da Univ São Paulo [Internet]. 2016;50(3):427-33. Disponível em: www.ee.usp.br/reeusp\%0Awww.ee.usp.br/reeus $\mathrm{p}$

11. Gomes HO, Brito JC, Gomes L. Trabalho e saúde das profissionais de enfermagem em urgência e emergência: estudo de caso em uma Unidade de Pronto Atendimento no Município do Rio de Janeiro". Dissertação (Mestrado) - Escola Nacional de Saúde Pública Sergio Arouca. 2014. p. 183f. Disponível em: https://bvssp.icict.fiocruz.br/lildbi/docsonline/ge t.php?id=4005

12. Mattos $\mathrm{P}$ de $\mathrm{C}$. Tipos de revisão de literatura. Fac Ciências Agron UNESP Campus Botucatu. 2015. Disponível em: www.fca.unesp.br/Home/Biblioteca/tipos-deevisao-de-literatura.pdf

13. Souza MT de, Silva MD da, Carvalho R de. Revisão integrativa: o que é e como fazer. 2010;8(1):102-6. Disponível em: http://www.scielo.br/scielo.php?script=sci_artte $x t \& p i d=\$ 1679$ -

45082010000100102\&lng=en\&nrm=iso\&tlng=en

14. Inoue KC, Murassaki ACY, Bellucci Júnior JA, Rossi RM, Martinez YDÉ, Matsuda LM. Acolhimento com classificação de risco: avaliação da estrutura, processo e resultado. REME Rev Min Enferm [Internet]. 2015;19(1):13-20. Disponível em: http://www.gnresearch.org/doi/10.5935/14152762.20150002 
15. Alves Roncalli A, Nogueira de Oliveira D, Melo IC, da Fonseca Viegas SM, Figueiredo Brito R. Experiências cotidianas do enfermeiro na classificação de risco em unidade de pronto atendimento. J Nurs UFPE / Rev Enferm UFPE [Internet]. 2017;11(4):1743-51. Disponível em: http://search.ebscohost.com/login.aspx?direct=t rue \&db=cin20\&AN=122432319\&site=ehost-live

16. Duro CLM, Lima MAD da S, Weber LAF. Opinião de enfermeiros sobre classificação de risco em serviços de urgência. REME Rev Min Enferm [Internet]. 2017;21:1-9. Disponível em: http://www.gnresearch.org/doi/10.5935/14152762.20170072

17. Roncalli AA, Oliveira DN de, Silva ICM, Brito RF, Viegas SM da F. Protocolo De Manchester E População Usuária Na Classificação De Risco: Visão Do Enfermeiro. Rev Baiana Enfermagem [Internet]. 2017;31(2). Disponível em:

https://portalseer.ufba.br/index.php/enfermage m/article/view/16949

18. Prudêncio CPG, Monteiro RA do N, Ribeiro BCM, Gomes MSM, Manhães LSP. Percepção De Enfermeira(o)s Sobre Acolhimento Com Classificação De Risco No Serviço De Pronto Atendimento. Rev Baiana Enfermagem [Internet]. 2016;30(2):1-10. Disponível em: http://www.portalseer.ufba.br/index.php/enfer magem/article/view/14917

19. Cavalcante, AKCB; Damasceno CAFM. Humanização Da Assistência Em Atendimento De Urgência Hospitalar : Percepção Dos Enfermeiros. Revista Baiana de Enfermagem. 2013;221-33. Disponível em: https://portalseer.ufba.br/index.php/enfermage $\mathrm{m} /$ article/view/8318/8421

20. Bellucci JA, Vituri DW, da Silva Versa GLG, Furuya PS, Vidor RC, Matsuda LM. Acolhimento com classificação de risco em serviço hospitalar de emergência: Avaliação do processo de atendimento. Rev Enferm. 2015;23(1):82-7. Disponível em: http://www.facenf.uerj.br/v23n1/v23n1a14.pdf 21. Neto $A V L$, Nunes VMA, Fernandes RL, Barbosa IML, Carvalho GRP. Acolhimento e humanização da assistência em pronto-socorro adulto: percepções de enfermeiros. Rev Enferm da UFSM. 2013;3(2):276-86. Disponível em: https://periodicos.ufsm.br/reufsm/article/view/8 279/pdf

22. Medeiros-Costa ME, Lima LL De, Freitas JG. A síndrome do esgotamento profissional no contexto da enfermagem: uma revisão integrativa da literatura. Rev da Esc Enferm da USP. 2017;51:1-12. Disponível em: http://www.scielo.br/pdf/reeusp/v51/pt_1980-
220X-reeusp-51-e03235.pdf

23. Seoane AF, Fortes PA de C. Percepção de médicos e enfermeiros de unidades de assistência médica ambulatorial sobre humanização nos serviços de saúde. Saude e Soc. 2014;23(4):1408-16. Disponível em: http://www.scielo.br/pdf/sausoc/v23n4/01041290-sausoc-23-4-1408.pdf

\section{Endereço para Correspondência}

Universidade Estadual De Santa Cruz - UESC

Rod. Jorge Amado, Km 16 - Salobrinho

Ilhéus - BA

CEP.: 45662-900

e-mail: rafalorena10@hotmail.com

Recebido em 20/09/2018

Aprovado em 22/10/2019

Publicado em 13/02/2020 